\title{
Clinical outcome of skin yaws lesions after treatment with benzathinebenzylpenicillin in a pygmy population in Lobaye, Central African Republic
}

\author{
Alexandre Manirakiza ${ }^{1 *}$, Susana Vilas Boas ${ }^{2}$, Narcisse Beyam ${ }^{3}$, Germain Zadanga ${ }^{1}$, François Xavier Konamna', \\ Siméon P Njuimo ${ }^{1}$ and Rémi Laganier ${ }^{1}$
}

\begin{abstract}
Background: Yaws is a bacterial skin and bone infectious disease caused by Treponema pallidum pertenue. It is endemic, particularly among pygmies in Central African Republic. To assess the clinical cure rate after treatment with benzathinepenicillin in this population, we conducted a cohort survey of 243 patients in the Lobaye region.

Findings and conclusion: The rate of healing of lesions after 5 months was $95.9 \%$. This relatively satisfactory level of therapeutic response implies that yaws could be controlled in the Central African Republic. Thus, reinforcement of the management of new cases and of contacts is suggested.
\end{abstract}

Keywords: Yaws, Treatment, Central African Republic

\section{Background}

Yaws is a skin and bone non-venereal treponematosis caused by Treponema pallidum subsp. pertenue. It is not considered a neglected disease, but a forgotten one $[1,2]$. Most infected people reside in warm, humid tropical areas, in communities with lack of hygiene [3]. The usual means of transmission of yaws is close bodily contact with a patient with infectious lesions [4]. The clinical features are classified in stages [1,5]. During the primary stage, a lesion called the 'mother yaw' occurs as a papule, which develops after 2-4 weeks of incubation at the site of Treponema inoculation and enlarges before it ulcerates. Spontaneous resolution occurs after almost 6 months, and the initial lesion heals. The secondary stage is characterized by widespread smaller skin papules, the 'daughter yaws'. After a variable latency, which can last several years, a late stage develops in $10 \%$ of patients, which consists of skin ulceration, gumma formation and destruction of bones and cartilage.

* Correspondence: amanirak@yahoo.fr

${ }^{1}$ Institut Pasteur de Bangui, PO Box 923, Bangui, Central African Republic Full list of author information is available at the end of the article
Painful palmoplantar hyperkeratosis and keratoderma are also observed during this third stage.

Basically, the diagnosis of an infection by Treponema pertenue is based on three criteria,(i) the emergence of the disease in an endemic region, (ii) clinically typical papilloma lesions, and (iii) seroactivity in a treponemal antigen test [6]. The operational definition of a case of yaws is "any person who lives in an endemic area and presents with one or more of the following signs: painless ulcer with scab, papilloma, palmar/plantar hyperkeratosis (thickening)" [2].

Clinical diagnosis is reliable with minimal training of health staff. In the field, diagnosis is based mainly on clinical findings and epidemiology. The diagnostic terms suggestive of active yaws proposed for use in mass campaigns [7-9] are (i) initial lesions of nongenital chancre, painless, non-tender papule with a raised margin; (ii) multiple papillomata; (iii) plantar and palmar papillomata; (iv) hyperkeratosis and (v) gummata, ulcers and gangosa.

The elimination and ultimate eradication of the infection require strategies targeted against the factors that favour its transmission. Thus, control activities must be 
considered in mass treatment campaigns to eliminate the source of infection, with improved environmental and individual hygiene [10]. Benzathinebenzylpenicillin is the currently recommended antibiotic for use against yaws [11].

Mass campaigns carried out in yaws endemic areas since the 1950's gave rise to the possibility of eradication of this infection $[11,12]$. Recently, however, resurgence of yaws has been reported [13-15], due to curtailment of control activities, which has allowed the reservoir of untreated yaws to grow unchecked.

Yaws is endemic in central Africa [16]. In the Central African Republic (CAR), pygmies are the most widely infected segment of the population [6]. In a serological survey performed between November 1978 and March 1979 in the pygmy population of southwest CAR (Lobaye and Sangha), the prevalence of clinically diagnosed yaws was $50 \%$, with positive serology rates of $86 \%$ in children and $95 \%$ in adults [17]. In the same area, Cirera et al. showed that $78.5 \%$ of pygmy children had sera positive for Treponema, suggesting massive infestation with $T$. pertenue [18]. Mass treatment campaigns were carried out in those regions between 1977 and 1980 (CAR Health Ministry, unpublished data). In 1992, a resurgence of yaws was reported in this area [15], but no further control activities were conducted.

Treatment of yaws with benzathinebenzylpenicillin is included in CAR Ministry of Health guidelines; however, the outcome of patients treated with this antibiotic has never been assessed. The aim of this study was to evaluate the clinical evolution of yaws skin lesions after administration of benzathinebenzylpenicillin in a pygmy population.

\section{Methods}

\section{Study area}

A treatment campaign against yaws was conducted in Mongoumba (Figure 1), a district in the Lobaye region in southwest CAR close to the borders with the Democratic Republic of the Congo and the Congo. The climate is equatorial. The total population is estimated at 21235 inhabitants, $15 \%(n=3089)$ of whom are pygmies. In this area, there are two health centres: the Santé Saint Georges, which is a private health centre run by Comboni Missionaries whose aim is to improve the social integration of pygmies; and the Mongoumba Health Centre, which is a public institution of the CAR Ministry of Health.

Staff of Santé Saint Georges visit pygmies in their settlements, dispersed throughout the forest, to advise

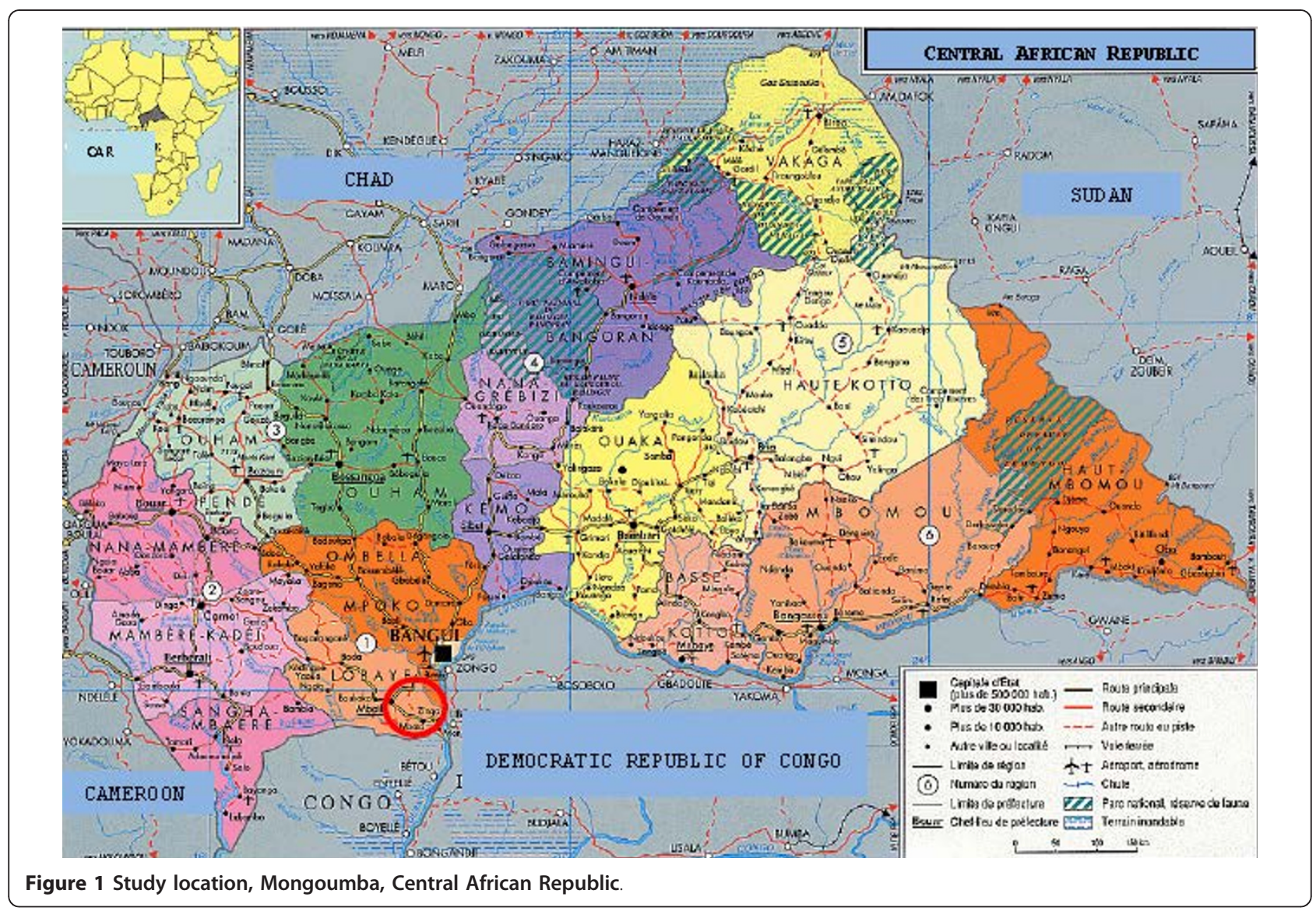


them on hygiene and health services. Patients are invited to present themselves to either the Santé Saint Georges or the Mongoumba health centre.

\section{Case diagnosis}

Between November 2007 and March 2008, a cohort of pigmies presenting with skin lesions was constituted. The inclusion criteria were skin lesions clinically suggestive of yaws or any other non-traumatic skin lesions that could not be classified but which scored positive on serological analysis with both the venereal disease research laboratory (VDRL) test and the T. pallidum haemagglutination (TPHA) test.

All 254 pygmies in 18 settlements in the Mongoumba region with these types of skin lesion were recruited. Of these, 191 had skin lesions clinically suggestive of yaws, and $63 \mathrm{had}$ other skin lesions. Assuming that Treponema serology was likely to be positive in people with skin lesions clinically suggestive of yaws $[17,18]$, we did not collect blood samples for serological diagnosis in these cases; however, a 5-ml venous blood sample was collected from each of the 63 pygmies with atypical skin lesions and tested at the Institut Pasteur de Bangui. Both tests were positive in 52 patients, three were positive with TPHA and negative with VDRL, and eight samples were negative with both tests. The patients positive in both tests were considered to have active yaws. Thus, a cohort of 243 patients was constituted to assess scarring of skin lesions after injection of one dose of benzathinebenzylpenicillin.

\section{Treatment and follow-up}

During April 2008, a single dose of benzathinebenzylpenicillin was administered intramuscularly to each of the 243 patients in our study cohort and to contacts not presenting any skin lesions. The doses administered were $2.4 \mathrm{M}$ units for adults, $1.2 \mathrm{M}$ units for children and $0.6 \mathrm{M}$ units for infants. Some pygmies were absent during this treatment campaign. Hence, a total of 2456 pygmies in the Mongoumba area (79.5\% or $2456 / 3089)$ were treated during the 6-month campaign. Follow-up of those pigmies with skin lesions was conducted at the Santé Saint Georges health centre, with no follow-up in the settlements. Clinical outcome (total scarring of skin lesions) was assessed 2-5 months later (July-September 2008).

\section{Ethical approval and consent to participate}

Because there was no national ethical committee in the CAR during the period in which this survey was conducted, the project was approved by the expert committee for drug policy and the Ministry of Health in the CAR. The aim of the survey and all the procedures (clinical examination, probable collection of blood samples for laboratory investigation of yaws, injection of the antibiotic into the gluteal muscle, use of photographs for possible publication and duration of followup) were explained in the native Aka language during meetings organized by our study team. Oral consent was collected from all participants, none of whom was literate.

\section{Findings}

In this study, we observed no lost of follow-up. The mean age of patients was 16 years (median, 20 years) and the male: female ratio was 1.15. Initial yaws skin lesions were found in 135 (55.6\%) cases, multiple papillomata (Figure 2) in $12.3 \%$, plantar and palmar papillomata in $5.3 \%$, hyperkeratosis in $2.5 \%$ and ulcers in $2.9 \%$; the remaining cases, classified as atypical lesions, represented $21.4 \%$. There was no statistically significant difference in the distribution of clinical stages by sex $(p=$ $0.6)$. Initial yaws lesions were more frequent among children $<17$ years $(74.5 \%$ or $82 / 110)$ than in other age categories $(p<0.0001)$ (Figure 3$)$.

Overall, 95.9\% (233/243) of the skin lesions had scarred during the period before outcome assessment (Figure 4); 10 patients presented with persistent skin lesions at the end of assessment, all located on the feet and complicated by ulcers. These persistent lesions had been classified at baseline as initial lesions $(5.2 \%$ or $7 /$ 135), multiple papillomata (3.3\% or $1 / 30)$ and atypical skin lesions $(3.8 \%$ or $2 / 52)$. Persistent lesions were followed up and dressed regularly at the Santé Saint Georges health centre.

The additional file 1 (as Excel xls file) provide details on data of this study.

\section{Discussion}

There is a suspected emergence of Treponema pertenue resistance to benzathinebenzylpenicillin [19]. Hence, it was essential to assess clinical evolution of skin lesions of yaws after treatment with benzathinebenzylpenicillin. Our findings show that relatively few skin lesions persisted 5 months after administration of benzathinebenzylpenicillin in this study cohort. The persistent lesions might be treatment failures due to concurrent factors such as other infecting agents and microtrauma. All the persistent lesions were located on the feet, which are highly exposed because pygmies rarely wear shoes and their economy is based on hunting in the equatorial forest. It is possible that T. pallidum pertenue developed resistance to benzathinebenzylpenicillin in these cases, as reported by Backhouse in Papua New Guinea $[19,20]$.

A potential limitation of this study is that serological tests were not performed systematically in all patients to support a diagnosis of yaws, and clinical diagnosis might have led to overestimation of the number of cases. In 


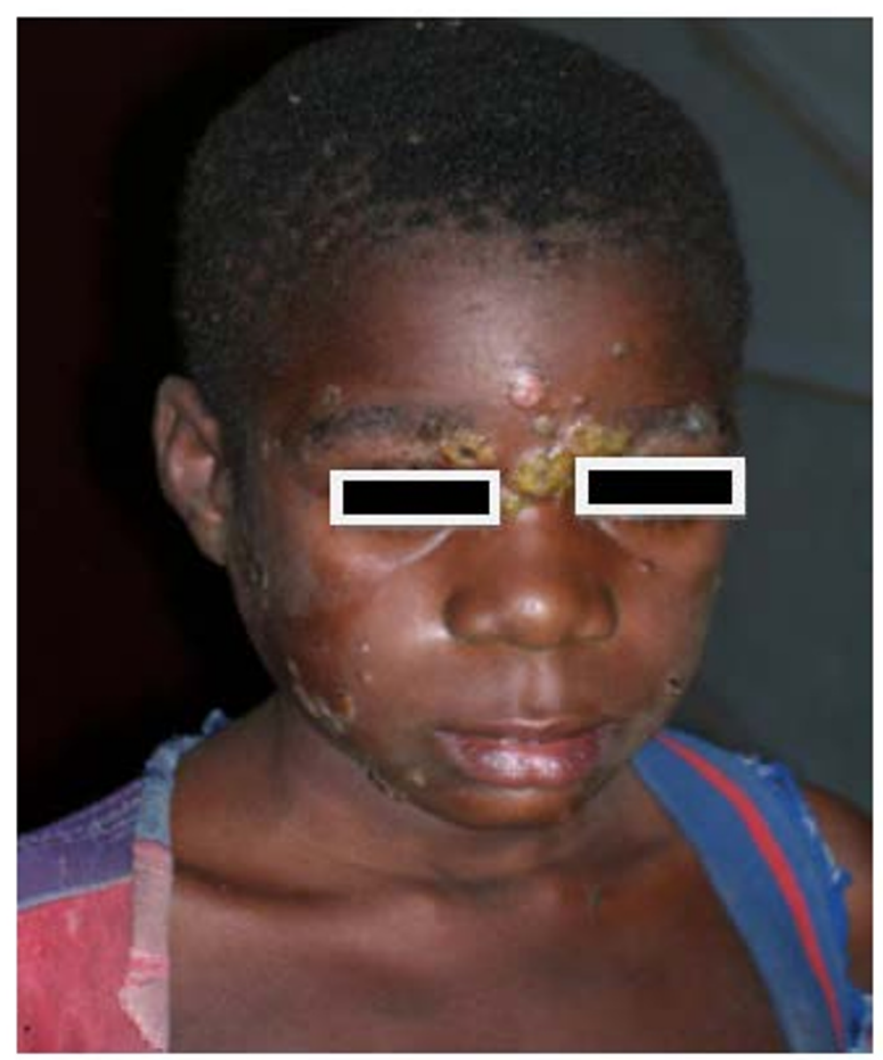

Figure 2 Active yaws lesions, Mongoumba, Central African Republic, December 2007 (photograph by S.V. Boas).

this endemic context, however, skin lesions are highly predictive of yaws [17]. Moreover, we found $82.5 \%$ positive serology with both VDRL and TPHA in patients with atypical lesions clinically suggestive of yaws. A second potential limitation is that the outcome was not assessed from VDRL titres after treatment but only from healing of skin lesions. Use of VDLR titres could be justified in chronic infections involving the bones [19], because of low bone penetration of penicillin [21]. Scarring of skin lesions can be attributed to killing of the microbes by benzathinebenzylpenicillin a few months after its administration to patients, even if spontaneous resolution of some primary lesions occurred. Moreover, no new skin lesions suggestive of yaws were registered at Santé Saint Georges or in the pygmy settlements at the time we measured clinical outcome. Therefore, the mass campaign with benzathinebenzylpenicillin prevented any new infections, suggesting its efficacy.

The high proportion (26.5\%) of initial lesions in people aged over 17 years is surprising. In this region, a diagnosis of yaws can be differentiated from primary lesions of tropical ulcers [22,23], hence, usefulness of serological tests to overcome this difficulty with diagnosis.
Although the coverage rate of our mass treatment campaign was almost $80 \%$, there could be latent yaws lesions in the untreated pygmies, constituting a source of resurgence of active yaws lesions in Mongoumba. The scarring rate observed in this cohort survey indicates that mass campaigns could eradicate this infectious disease. It is, however, not easy to give health advice to pygmies who live in the forest. Continued interruption of transmission and eradication depend on the availability of personnel and environmental sanitation.

\section{Conclusion}

This survey showed a high rate of efficacy of benzathinebenzylpenicillin in healing yaws. Our findings also show that yaws is presumably still highly prevalent in this area, especially in the pygmy population, due to their poor personal and environmental hygiene. As spread of this infection to other contact groups in the country is possible, ongoing activities to improve social conditions and surveillance and prompt treatment of new yaws cases and all contacts are necessary in the endemic areas of CAR. The CAR health Ministry should introduce yaws control activities in the primary health 


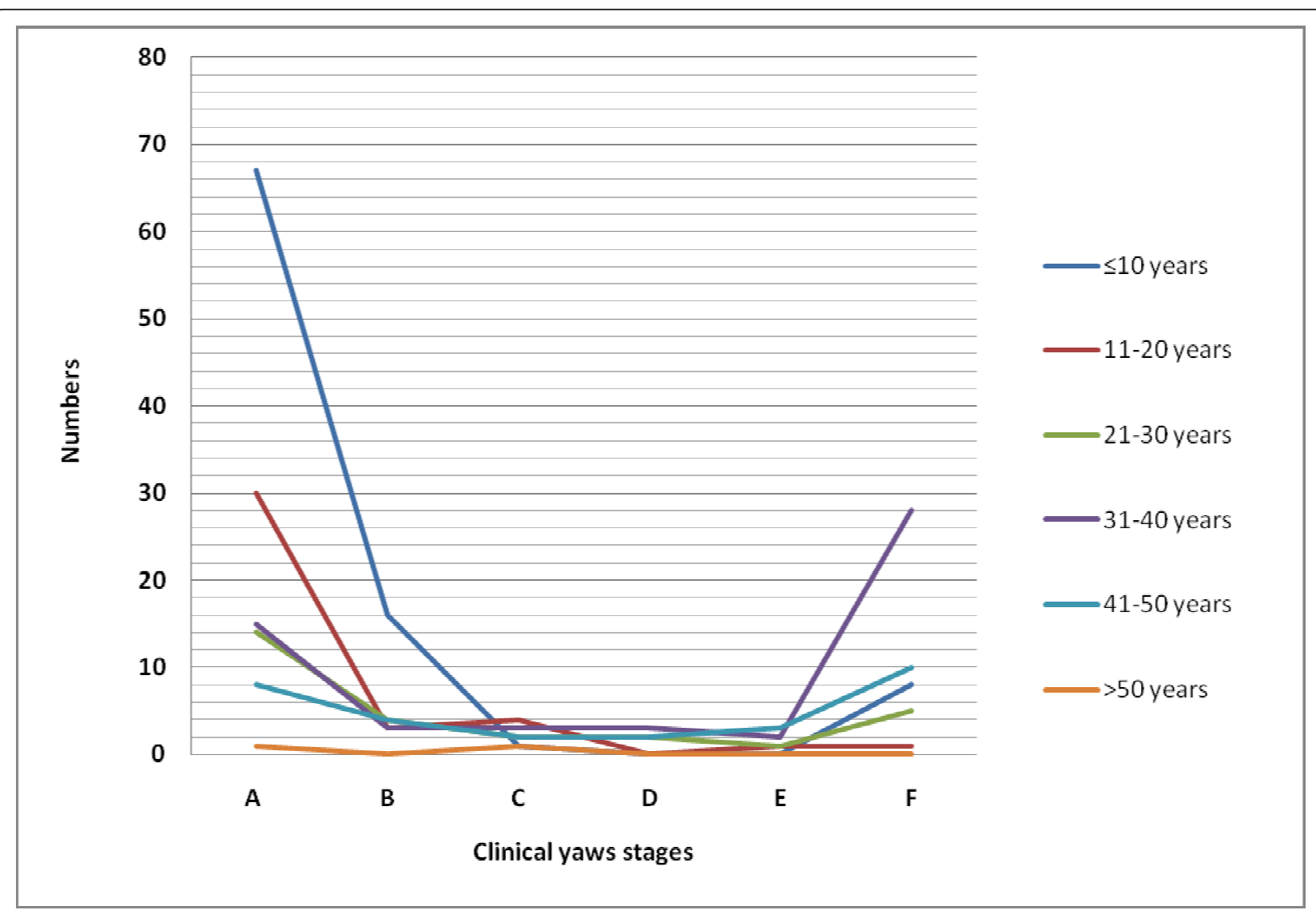

Figure 3 Age distribution by stage of yaws in 243 patients, Central African Republic, December 2007-September 2008.

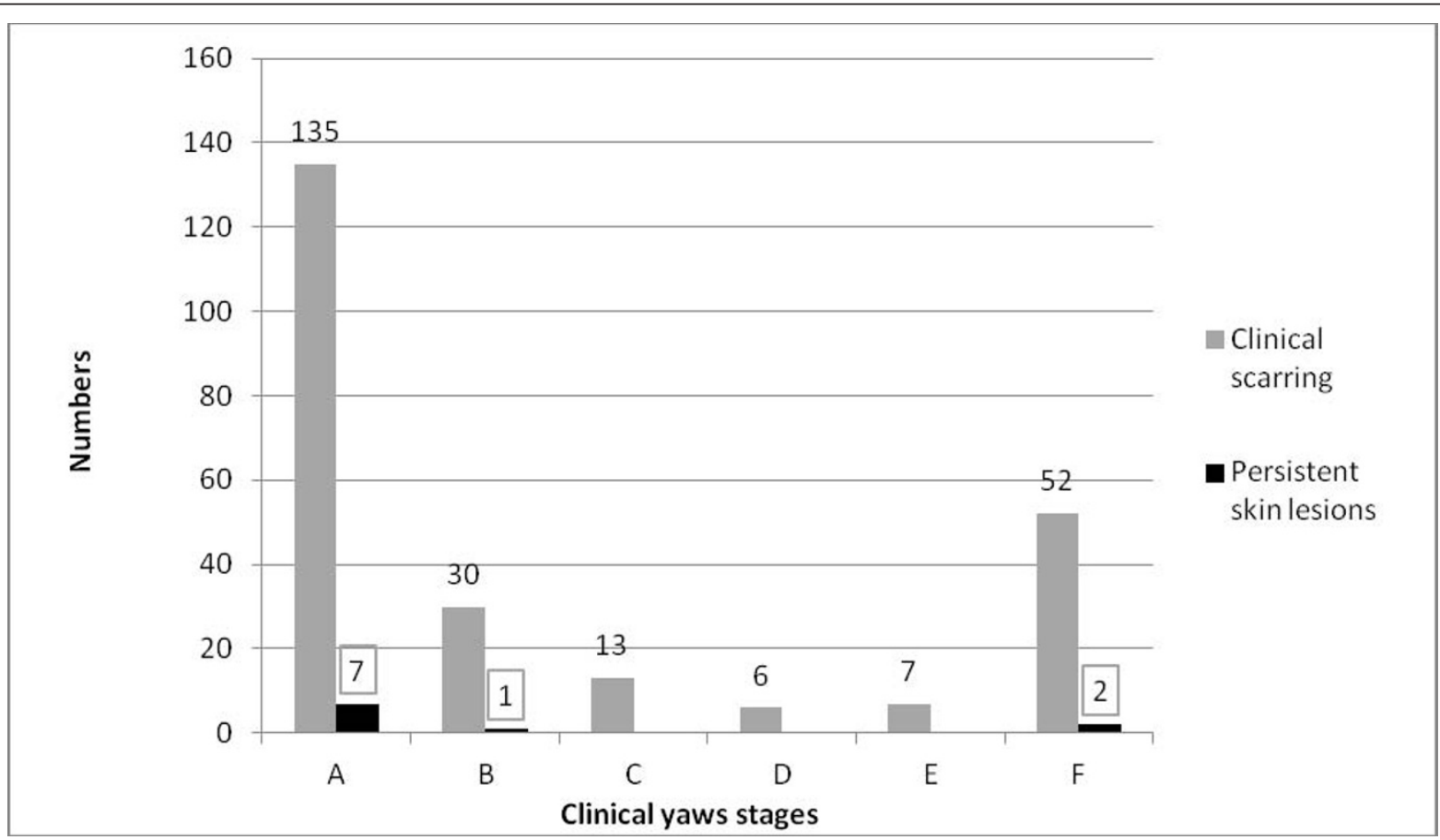

Figure 4 Clinical healing after treatment of yaws in 243 patients, Central African Republic, December 2007-September 2008 
care and further serological studies to assess the efficacy of benzathinebenzylpenicillin are also needed, with assessment of the bone stage of yaws.

\section{Additional material}

Additional file 1: Clinical yaws stage: $A$, initial lesions; $B$, multiple papillomata; C, plantar and palmar papillomata; D, hyperkeratosis: $E$, gummata, ulcers or gangosa; $F$, atypical skin lesions.

\section{Acknowledgements}

We thank the patients and the Mongoumba 'Caritas' personnel for their participation in this campaign and Gilbert Hakizimana for critical reading of the manuscript. We also thank Jean Baptiste Zitongo for technical support during our field missions.

We are very thankful to Dr Elisabeth Heseltine (http://www. communicationinscience.com) and Dr Mirdad Kazanji for critical reading of the manuscript.

This study received financial and technical support from the Institut Pasteur de Bangui and medical assistance from the Boali detachment of the French Army Corps in the CAR.

\section{Author details}

${ }^{1}$ Institut Pasteur de Bangui, PO Box 923, Bangui, Central African Republic. ${ }^{2}$ Poste de santé de Mongoumba, Bangui, Central African Republic. ${ }^{3}$ United Nations Population Fund, Bangui, Central African Republic.

\section{Authors' contributions}

AM and SVB conceived the study, did the data management and drafted the paper. The field study was conducted by AM, SVB, NB, GZ, FXK and SPN. $\mathrm{RL}$ participated in laboratory analysis and interpretation. AM and SVB prepared this draft. All authors read and approved the final manuscript.

\section{Competing interests}

The authors declare that they have no competing interests.

Received: 24 August 2011 Accepted: 15 December 2011

Published: 15 December 2011

\section{References}

1. Rinaldi A: Yaws: a second (and maybe last?) chance for eradication. PLoS Neglected Tropical Diseases 2008, 2(8):e275.

2. WHO: Yaws: A forgotten disease. Fact sheet N³16, January 2007 2007, accessed at http://www.who.int/mediacentre/factsheets/fs316/en/ on July 10, 2011.

3. Sehgal VN, Jain S, Bhattacharya SN, Thappa DM: Yaws control/eradication. Int J Dermatol 1994, 33(1):16-20.

4. Hackett CJ, Guthe T: Some important aspects of yaws eradication. Bull World Health Organization 1956, 15(6):869-896.

5. Walker SL, Hay RJ: Yaws-a review of the last 50 years. Int J Dermatol 2000, 39(4):258-260.

6. Martin PM, Gonzalez JP, Martin MH, Georges-Courbot MC, Palisson MJ, Georges AJ: Clinical aspects and usefulness of indirect absorbed immunofluorescence for diagnosis of yaws in Central Africa. J Clin Microbiol 1988, 26(11):2432-2433.

7. World Health organization, WIrd HIth Org. Techn.Rep.Ser. 63. 1953.

8. Hackett CJ: Some epidemiological aspects of yaws eradication. Bulletin of the World Health Organization 1960, 23:739-761.

9. Perine PL, Hopkins DR, Niemel PL, StJohn LK, Causse G, Antal GM: Manuel des tréponematoses endemiques: pian, syphilis endémiques et pinta. Organisation Mondiale de la Santé 1985, 107.

10. Troupin JL, Reynolds FW, Guthe T: Yaws control; an opportunity for promoting rural health-services. Bulletin of the World Health Organization 1953, 8(1-3):355-368
11. Asiedu K, Amouzou B, Dhariwal A, Karam M, Lobo D, Patnaik S: Yaws eradication: past efforts and future perspectives. Bull World Health Organ 2008, 86:499-499A

12. Williams G: WHO-the days of the mass campaigns. World Health Forum 1988, 9(1):7-23.

13. Tharmaphornpilas $P$, Srivanichakorn S, Phraesrisakul N: Recurrence of yaws outbreak in Thailand, 1990. The Southeast Asian J Trop Med Public Health 1994, 25(1):152-156.

14. Agadzi VK, Aboagye-Atta Y, Nelson JW, Perine PL, Hopkins DR: Resurgence of yaws in Ghana. Lancet 1983, 2(8346):389-390.

15. Herve V, Kassa Kelembho E, Normand P, Georges A, Mathiot C, Martin P: [Resurgence of yaws in Central African Republic. Role of the Pygmy population as a reservoir of the virus]. Bull Soc Pathol Exot 1992, 85(5):342-346

16. Pampiglione $\mathrm{S}$, Wilkinson $\mathrm{AE}$ : A study of yaws among pygmies in Cameroon and Zaire. Br J Vener Dis 1975, 51(3):165-169.

17. Widy-Wirski R, D'Costa J, Meheus A: [Prevalence of yaws in pygmies of the Central African Republic]. Ann Soc Belg Med Trop 1980, 60(1):61-67.

18. Cirera P, Palisson MJ, Pinerd G, Jaeger G: [Treponemal serology in a Bi-Aka pygmy population of Central Africa].70.

19. Mitja O, Hays R, Ipai A, Gubaila D, Lelngei F, Kiara M, Paru R, Bassat Q: Outcome predictors in treatment of yaws. Emerging Infectious Diseases 2011, 17(6):1803-1085

20. Backhouse JL, Hudson BJ, Hamilton PA, Nesteroff SI: Failure of penicillin treatment of yaws on Karkar Island, Papua New Guinea. The Am J Trop Med Hyg 1998, 59(3):388-392.

21. Landersdorfer CB, Bulitta JB, Kinzig M, Holzgrabe U, Sorgel F: Penetration of antibacterials into bone: pharmacokinetic, pharmacodynamic and bioanalytical considerations. Clinical Pharmacokinetics 2009, 48(2):89-124.

22. Minime-Lingoupou F, Beyam N, Zandanga G, Manirakiza A, N'Domackrah A, Njuimo S, Eyangoh S, Cottin J, Marsollier L, Marion E, et al: Buruli ulcer, Central African Republic. Emerging Infectious Diseases 2010, 16(4):746-748.

23. Hackett CJ, Loewenthal LJ: Differential diagnosis of yaws. Monogr Ser World Health Organ 1960, 45:1-88.

\section{doi:10.1186/1756-0500-4-543}

Cite this article as: Manirakiza et al:: Clinical outcome of skin yaws lesions after treatment with benzathinebenzylpenicillin in a pygmy population in Lobaye, Central African Republic. BMC Research Notes 2011 4:543.

\section{Submit your next manuscript to BioMed Central and take full advantage of:}

- Convenient online submission

- Thorough peer review

- No space constraints or color figure charges

- Immediate publication on acceptance

- Inclusion in PubMed, CAS, Scopus and Google Scholar

- Research which is freely available for redistribution

Submit your manuscript at www.biomedcentral.com/submit
C Biomed Central 